\title{
ApoB/ApoA-I ratio is independently associated with carotid atherosclerosis in type 2 diabetes mellitus with well-controlled LDL cholesterol levels
}

\author{
Ji Eun Jun ${ }^{1}$, Young Ju Choi ${ }^{2}$, Yong-Ho Lee ${ }^{3}$, Dae Jung Kim ${ }^{4}$, Seok Won Park ${ }^{5}$, Byung Wook Huh², \\ Eun Jig Lee ${ }^{3}$, Sun-Ha Jee ${ }^{6}$, Kyu Yeon Hur ${ }^{1}$, Sung Hee Choi ${ }^{7}$, and Kap Bum Huh²
}

\begin{abstract}
${ }^{1}$ Division of Endocrinology and Metabolism, Department of Medicine, Samsung Medical Center, Sungkyunkwan University School of Medicine, Seoul; ${ }^{2}$ Huh's Diabetes Center and 21st Century Diabetes and Vascular Research Institute, Seoul; ${ }^{3}$ Division of Endocrinology and Metabolism, Department of Internal Medicine, Yonsei University College of Medicine, Seoul; ${ }^{4}$ Department of Endocrinology and Metabolism, Ajou University School of Medicine, Suwon; ${ }^{5}$ Department of Internal Medicine, CHA University, Seongnam; ${ }^{6}$ Department of Epidemiology and Health Promotion, Institute for Health Promotion, Yonsei University Graduate School of Public Health, Seoul; ${ }^{7}$ Department of Internal Medicine, Seoul National University Bundang Hospital, Seongnam, Korea
\end{abstract}

Received: November 28, 2017 Revised : December 12, 2017 Accepted: December 12, 2017

\author{
Correspondence to \\ Kyu Yeon Hur, M.D. \\ Division of Endocrinology and \\ Metabolism, Department of \\ Medicine, Samsung Medical Cen- \\ ter, Sungkyunkwan University \\ School of Medicine, 81 Irwon-ro, \\ Gangnam-gu, Seoul o6351, Korea \\ Tel: $+82-2-3410-1232$ \\ Fax: +82-2-3410-3849 \\ E-mail: ky.hur@samsung.com
}

Background/Aims: This study aimed to investigate whether the apolipoprotein (Apo) B/ApoA-I ratio is associated with carotid intima-media thickness (CIMT) in type 2 diabetes mellitus (T2DM) subjects with low density lipoprotein cholesterol (LDL-C) levels less than $100 \mathrm{mg} / \mathrm{dL}$.

Methods: This cross-sectional study included 845 subjects aged with T2DM 40 to 75 years who had visited Huh's Diabetes Center in Seoul, Republic of Korea for CIMT measurement. Traditional fasting lipid profiles, ApoB and ApoA-I levels were examined. CIMT was measured at three points on the far wall of $1 \mathrm{~cm}$ long section of the common carotid artery in the proximity of the carotid bulb. The mean value of six measurements from right and left carotid arteries were used as the mean CIMT. In this study, carotid atherosclerosis was defined as having a focal plaque or diffuse thickening of the carotid wall (mean CIMT $\geq 1.0 \mathrm{~mm}$ )

Results: The prevalence of carotid atherosclerosis increased with ApoB/ApoA-I ratio. The ApoB/ApoA-I ratio, expressed as both quartiles (odds ratio [OR], 2.14; 95\% confidence interval [CI], 1.21 to 3.79; $p$ for trend $=0.014$ ) and continuous values (OR, 10.05; $95 \%$ CI, 3.26 to $30.97 ; p<0.001$ ), was significantly associated with a higher risk for carotid atherosclerosis, regardless of conventional cardiovascular disease risk factors. The optimal ApoB/ApoA-I ratio cutoff value for detecting carotid atherosclerosis was 0.57 , based on receiver operating characteristic curve analysis with a sensitivity of $58.0 \%$ and a specificity of $55.1 \%$.

Conclusions: A high ApoB/ApoA-I ratio was significantly associated with carotid atherosclerosis in T2DM patients with LDL-C levels less than $100 \mathrm{mg} / \mathrm{dL}$.

Keywords: Apolipoprotein B/Apolipoprotein A-I ratio; Carotid intima-media thickness; Cholesterol, LDL; Diabetes mellitus, type 2 


\section{INTRODUCTION}

Low density lipoprotein cholesterol (LDL-C) is an independent determinant of cardiovascular disease (CVD). The American Diabetes Association recommends that a moderate intensity statin should be considered for patients aged 40 to 75 years with diabetes, even when additional CVD risk factors are not present [1]. Several other guidelines also include LDL-C as a primary target for initial lipid-lowering treatment [2-4]. However, LDL-C levels are not always elevated in patients with coronary heart disease (CHD) $[5,6]$. One possible explanation for this is that specific LDL sub-fractions, rather than total LDL-C, may be more important in atherosclerosis because small dense LDL particles can easily penetrate into the arterial wall and are more susceptible to oxidation [7]. In addition, substantial LDL-C heterogenicity was found in type 2 diabetes mellitus (T2DM) patients with LDL-C levels less than $100 \mathrm{mg} / \mathrm{dL}$ [8].

In addition to total cholesterol, different lipoprotein fractions can also inform CVD risk. A single molecule of apolipoprotein (Apo) B is present in each small dense LDL, and reflects the total number of atherogenic particles. In addition, ApoA-I transfers excess cholesterol to the liver from high density lipoprotein (HDL) particles [9]. Therefore, the ApoB/ApoA-I ratio is a marker of atherogenic and anti-atherogenic cholesterol balance in plasma $[10,11]$. Previous studies found that the ApoB/ ApoA-I ratio was significantly associated with the risk of fatal myocardial infarction (MI) regardless of conventional CVD risk factors [12,13], even when the levels of other lipids were within normal ranges [14]. Moreover, one study found that the ApoB/ApoA-I ratio was a superior predictor of CHD risk compared to the total cholesterol/HDL-C, LDL-C/HDL-C, and non HDL-C/HDL-C ratio [15].

Insulin resistance is related to abnormalities in plasma lipid and lipoprotein levels. Diabetic dyslipidemia is characterized by hypertriglyceridemia, low HDL-C, a predominance of small dense LDL, and normal to high LDL-C levels [16]. Therefore, the aim of this study was to investigate whether the ApoB/ApoA-I ratio is associated with subclinical atherosclerosis, as assessed by carotid intima-media thickness (CIMT) in T2DM patients with well-controlled LDL-C levels.

\section{METHODS}

\section{Study subjects}

In total, 3,637 subjects with T2DM aged 40 to 75 years, who visited Huh's Diabetes Center in Seoul, Republic of Korea from 2003 to 2008 and who had CIMT measurements, were retrospectively screened. Of these patients, 834 were excluded due to previous history of CVD ( $\mathrm{n}=$ 34), abnormal liver function tests such as elevated total bilirubin $>2.0 \mathrm{mg} / \mathrm{dL}$ or liver enzymes more than twice the upper normal limit $(\mathrm{n}=192)$, estimated glomerular filtration rate $<60 \mathrm{~mL} / \mathrm{min} / 1.73 \mathrm{~m}^{2}(\mathrm{n}=310)$, incomplete measurement of CIMT $(\mathrm{n}=44)$, and missing clinical variables $(\mathrm{n}=254)$. Subjects with LDL-C levels $\geq 100 \mathrm{mg} / \mathrm{dL}$ were also excluded $(n=1,885)$. In addition, subjects with triglycerides $(\mathrm{TG}) \geq 400 \mathrm{mg} / \mathrm{dL}(\mathrm{n}=12)$, and who took fibrates $(n=107)$, were excluded because hypertriglyceridemia can underestimate LDL-C levels [17]. Finally, 845 subjects (462 men and 383 women) were enrol led in the study (Supplementary Fig. 1), which was approved by the Institutional Review Board of Yonsei University (IBR NO. 4-2017-0288). Due to the retrospective nature of this study, the requirement for written informed consent was waived.

\section{Clinical variable measurement}

All blood samples were collected from the antecubital vein after an 8 to 12 hours overnight fast. Fasting plasma glucose, total cholesterol, TG, HDL-C, and LDL-C concentrations were measured enzymatically using a 747 chemical analyzer (Hitachi, Tokyo, Japan). ApoB and ApoA-I were measured using the 7080 chemical analyzer (Hitachi). Glycated hemoglobin (HbA1c) was determined using high-performance liquid chromatography method (Variant II, Greencross, Seoul, Korea). Fasting C-peptide levels were measured using a double-antibody radioimmunoassay (DiaSorin, Stillwater, MN, USA).

Insulin sensitivity was directly assessed with a short insulin tolerance test that measured the rate of plasma glucose disappearance (Kitt, \%/min) after intravenous injection of regular insulin ( $0.1 \mathrm{U} / \mathrm{kg}$ ) as described previously [18-21]. Blood was obtained just prior to insulin injection (o minute), and at 3, 6, 9, 12, and 15 minutes after the injection. Plasma glucose concentrations were determined immediately after sampling using Beckman glucose analyzer II (Beckman Ins., Fullerton, CA, USA) 
and then Kitt was calculated from the slope of the fall in log-transformed plasma glucose concentrations between 3 and 15 minutes using the following formula: Kitt (rate constant for plasma glucose disappearance $)=0.693 /$ $t_{1} / 2 \times 100(\% / \mathrm{min})$. We routinely infused $100 \mathrm{~mL}$ of $20 \%$ dextrose solution immediately after the test to avoid any potential hypoglycemia.

\section{CIMT measurement}

Both carotid arteries were scanned using a high-resolution real-time B-mode ultrasonography with a $10-\mathrm{MHz}$ linear transducer (LOGIQ 7, GE, Milwaukee, WI, USA), as previously described [21-24]. The CIMT was defined as the distance between the lumen-intima and media-adventitia interfaces $[25,26]$. CIMT was measured at three points on the far wall of $1 \mathrm{~cm}$ long section of the common carotid artery in the proximity of the carotid bulb. The mean value of six measurements from right and left carotid arteries were used as the mean CIMT [21]. Carotid plaque was defined as focal structures encroaching into the arterial lumen of at least $0.5 \mathrm{~mm}$ or $50 \%$ of the surrounding intima-media thickness value, or a thickness $>1.5 \mathrm{~mm}[26]$. In this study, carotid atherosclerosis was defined as having a carotid plaque or diffuse thickening of the carotid wall (mean CIMT $\geq 1$.0 $\mathrm{mm})[21,27]$.

\section{Statistical analyses}

Data are expressed as mean \pm standard deviation, medians (interquartile range), or numbers (\%). Differences between two groups were evaluated using a $t$ test or Mann-Whitney $U$ test for continuous variables, and by a chi-square test for categorical variables. One way analysis of variance was used to investigate differences in variables between ApoB/ApoA-I ratio quartiles. LDL-C levels were log-transformed due to the skewed distribution. Logistic regression analyses were conducted to examine the correlations between ApoB/ApoA-I ratio and the prevalence of carotid atherosclerosis, with and without adjustment for conventional CVD risk factors. The strength of the association between the ApoB/ApoA-I ratio and mean CIMT was tested by Pearson correlation analysis. A variance of inflation factor > 5.0 was used as an indicator of multicollinearity. To evaluate the utility of the ApoB/ApoA-I ratio as a marker for carotid atherosclerosis, we used receiver operating characteristic (ROC) curves and calculated the area under the curve (AUC). All statistical analyses were performed using SPSS version 23.0 (IBM Co., Armonk, NY, USA) and STATA software version 13.0 (StataCorp LP, College Station, TX, USA). A $p$ value of $<0.05$ was considered significant.

\section{RESULTS}

\section{Baseline characteristics of all subjects}

Baseline characteristics of the subjects with or without carotid atherosclerosis are shown in Table 1. The mean age of all subjects was 57.2 years, the mean body mass index (BMI) was $24.3 \mathrm{~kg} / \mathrm{m}^{2}$, and the median LDL-C level was $84.0 \mathrm{mg} / \mathrm{dL}$. Subjects with carotid atherosclerosis were older, had higher BMIs and systolic blood pressure (BP), had experienced diabetes for a longer duration, had higher C-peptide levels, and were more insulin resistant. The proportion of men, statin use, and anti-hypertensive drug use were significantly higher among subjects with carotid atherosclerosis. HDL-C, LDL-C, ApoB, and the ApoB/ApoA-I ratio were also higher in subjects with carotid atherosclerosis, while ApoA-I was lower. There was no remarkable difference in total cholesterol or TG, use of thiazolidinedione or smoking status between groups.

When the subjects were divided into quartiles based on their ApoB/ApoA-I ratios (Table 2), the prevalence of carotid atherosclerosis significantly increased across quartiles. BMI, proportion of men, TG levels, LDL-C levels, and C-peptide increased, while HDL-C and Kitt decreased across quartiles.

\section{Prevalence of carotid atherosclerosis by ApoB/ ApoA-I ratio quartile and LDL-C}

Fig. 1 shows the percentage of patients with carotid atherosclerosis by ApoB/ApoA-I ratio quartile and LDL-C level. The percentage of patients with carotid atherosclerosis (54.5\%) was highest in subjects with high ApoB/ ApoA-I ratios (range, 0.71 to 1.59) and high LDL-C levels (range, 92 to $100 \mathrm{mg} / \mathrm{dL}$ ). The ApoB/ApoA-I ratio was consistently associated with the prevalence of carotid atherosclerosis in T2DM patients with LDL-C level less than $100 \mathrm{mg} / \mathrm{dL}$. However, higher LDL-C levels were not always associated with a higher prevalence of carotid atherosclerosis among them (Fig. 1). 
Table 1. Clinical characteristics of type 2 diabetes patients according to the prevalence of carotid atherosclerosis

\begin{tabular}{|c|c|c|c|c|}
\hline \multirow{2}{*}{ Characteristic } & \multirow{2}{*}{ Total } & \multicolumn{2}{|c|}{ Carotid atherosclerosis $^{\mathrm{a}}$} & \multirow{2}{*}{$p$ value } \\
\hline & & No & Yes & \\
\hline No. of patients & 845 & $520(61.7)$ & $325(38.3)$ & \\
\hline Age, yr & $57.2 \pm 8.3$ & $55.1 \pm 8.0$ & $60.5 \pm 7.6$ & $<0.001$ \\
\hline Male sex & $462(54 \cdot 7)$ & $268(51.5)$ & $194(59 \cdot 7)$ & 0.021 \\
\hline Body mass index, $\mathrm{kg} / \mathrm{m}^{2}$ & $24.3 \pm 3.2$ & $24.1 \pm 3 \cdot 3$ & $24.7 \pm 3.0$ & 0.009 \\
\hline $\mathrm{SBP}, \mathrm{mmHg}$ & $133.2 \pm 17.3$ & $131.1 \pm 17.0$ & $136.6 \pm 17.1$ & $<0.001$ \\
\hline $\mathrm{DBP}, \mathrm{mmHg}$ & $85.6 \pm 11.4$ & $85.4 \pm 11.4$ & $85.8 \pm 11.5$ & 0.629 \\
\hline DM duration, yr & $8.1 \pm 7 \cdot 3$ & $7.0 \pm 6.7$ & $9.8 \pm 7.9$ & $<0.001$ \\
\hline Use of statins & $163(19 \cdot 3)$ & $86(16.5)$ & $77(23.7)$ & 0.010 \\
\hline Use of anti-hypertensive drugs & $258(30.5)$ & $139(26.7)$ & $119(36.6)$ & 0.002 \\
\hline Use of insulin & $95(11.2)$ & $53(10.2)$ & $42(12.9)$ & 0.222 \\
\hline Use of TZD & $95(11.2)$ & $52(10.0)$ & $43(13.2)$ & 0.148 \\
\hline Current smoker $^{\mathrm{b}}$ & $112(24.2)$ & $70(26.4)$ & $42(21.3)$ & 0.207 \\
\hline HbAıc, \% & $7 \cdot 9 \pm 1.7$ & $7.8 \pm 1.8$ & $8.0 \pm 1.6$ & 0.107 \\
\hline Fasting glucose, mg/dL & $148.3 \pm 54.0$ & $148.0 \pm 54.8$ & $149.0 \pm 52.8$ & 0.813 \\
\hline Total cholesterol, mg/dL & $160.2 \pm 21.8$ & $159 \cdot 5 \pm 21.9$ & $161.5 \pm 21.6$ & 0.188 \\
\hline Triglycerides, mg/dL & $132.9 \pm 72.1$ & $128.9 \pm 72.1$ & $139 \cdot 3 \pm 71.6$ & 0.041 \\
\hline $\mathrm{HDL}-\mathrm{C}, \mathrm{mg} / \mathrm{dL}$ & $52.3 \pm 15 \cdot 3$ & $53.6 \pm 15.4$ & $50.3 \pm 14.9$ & 0.002 \\
\hline LDL-C, mg/dL & $84.0(71.0-92.0)$ & $83.0(70.0-92.0)$ & $86.0(75.0-92.0)$ & 0.017 \\
\hline ApoB, mg/dL & $80.8 \pm 19.5$ & $78.5 \pm 18.8$ & $84.4 \pm 20.1$ & $<0.001$ \\
\hline ApoA-I, mg/dL & $138.4 \pm 27.8$ & $140.9 \pm 28.4$ & $134.4 \pm 26.4$ & 0.001 \\
\hline ApoB/ApoA-I ratio & $0.61 \pm 0.18$ & $0.58 \pm 0.17$ & $0.65 \pm 0.20$ & $<0.001$ \\
\hline C-peptide, ng/mL & $1.8 \pm 0.8$ & $1.8 \pm 0.8$ & $1.9 \pm 0.8$ & 0.029 \\
\hline Kitt, \%/min & $2.2 \pm 1.0$ & $2.3 \pm 1.0$ & $2.1 \pm 1.0$ & 0.001 \\
\hline
\end{tabular}

Values are presented as number (\%), mean $\pm \mathrm{SD}$, or median (interquartile range).

SBP, systolic blood pressure; DBP, diastolic blood pressure; DM, diabetes mellitus; TZD, thiazolidinedione; HbAıc, glycated hemoglobin; HDL-C, high density lipoprotein cholesterol; LDL-C, low density lipoprotein cholesterol; Apo, apolipoprotein; Kitt, rate constant for plasma glucose disappearance.

${ }^{a}$ Carotid atherosclerosis is defined as carotid intima-media thickness $\geq 1.0 \mathrm{~mm}$ or presence of plaque.

${ }^{b}$ Value was measured in 462 subjects.

\section{The risk for carotid atherosclerosis according to ApoB/ApoA-I ratio}

The association between the ApoB/ApoA-I ratio and carotid atherosclerosis was analyzed by logistic regression analyses. Univariate logistic regression analyses revealed that age, male sex, duration of diabetes, BMI, systolic BP, TG, HDL-C, log-transformed LDL-C, C-peptide, Kitt, use of anti-hypertensive drugs, use of statins, ApoB, ApoA-I, and ApoB/ApoA-I ratio were significant risk factors for carotid atherosclerosis (Supplementary Table 1). Multivariate logistic regression analyses (Table 3,
Models 1 to 4) showed that a higher ApoB/ApoA-I ratio, expressed both as quartile and continuous values, was significantly associated with a higher risk of carotid atherosclerosis, regardless of age, sex, BMI, systolic BP, duration of diabetes, use of statins, use of anti-hypertensive drugs, TG, HDL-C, log-transformed LDL-C, or Kitt. These factors were all significant based on the univariate logistic regression analyses, along with $\mathrm{HbA1c}$, and are known risk factors for atherosclerosis (Model 4). The association between the ApoB/ApoA-I ratio and carotid atherosclerosis was still significant in males (odds ratio 
Table 2. Baseline characteristics of total subjects according to apolipoprotein B/apolipoprotein A-I ratio quartiles

\begin{tabular}{|c|c|c|c|c|c|}
\hline Variable & $\begin{array}{l}\text { Quartile } 1 \\
\text { (0.16-0.48) }\end{array}$ & $\begin{array}{l}\text { Quartile } 2 \\
(0.49-0.57)\end{array}$ & $\begin{array}{l}\text { Quartile } 3 \\
\left(0.5^{8}-0.70\right)\end{array}$ & $\begin{array}{l}\text { Quartile } 4 \\
(0.71-1.59)\end{array}$ & $p$ value \\
\hline No. of patients & 211 & 211 & 214 & 209 & \\
\hline Mean CIMT ${ }^{\mathrm{a}}, \mathrm{mm}$ & $0.84 \pm 0.14$ & $0.89 \pm 0.19$ & $0.90 \pm 0.19$ & $0.93 \pm 0.23$ & $<0.001$ \\
\hline Presence of plaque ${ }^{b}$ & $3(1.4)$ & $7(3 \cdot 3)$ & $6(2.8)$ & $17(8.1)$ & 0.001 \\
\hline Carotid atherosclerosis ${ }^{c}$ & $54(25 \cdot 6)$ & $81(38.4)$ & $90(42.1)$ & $100(47.8)$ & $<0.001$ \\
\hline Age, yr & $57.6 \pm 7.6$ & $57.5 \pm 8.3$ & $56.9 \pm 8.3$ & $56.6 \pm 8.8$ & 0.545 \\
\hline Male sex & $89(42.2)$ & $111(52.6)$ & $136(63.6)$ & $126(60.3)$ & $<0.001$ \\
\hline Body mass index, $\mathrm{kg} / \mathrm{m}^{2}$ & $23 \cdot 5 \pm 3 \cdot 3$ & $24.0 \pm 3.0$ & $24.6 \pm 2.9$ & $25.1 \pm 3.3$ & $<0.001$ \\
\hline $\mathrm{SBP}, \mathrm{mmHg}$ & $132.8 \pm 19.0$ & $132.1 \pm 17.3$ & $134.1 \pm 17.5$ & $133 \cdot 9 \pm 15.0$ & 0.592 \\
\hline DBP, mmHg & $85.6 \pm 12.1$ & $84.5 \pm 11.7$ & $86.2 \pm 11.7$ & $85.9 \pm 10.1$ & 0.492 \\
\hline DM duration, yr & $7 \cdot 9 \pm 7 \cdot 2$ & $8.7 \pm 7.6$ & $7 \cdot 5 \pm 7 \cdot 1$ & $8.2 \pm 7.5$ & 0.454 \\
\hline Use of statins & $39(18.5)$ & $48(22.7)$ & $41(19.2)$ & $35(16.7)$ & 0.472 \\
\hline Use of anti-hypertensive drugs & $58(27 \cdot 5)$ & $74(35.1)$ & $65(30.4)$ & $61(29.2)$ & 0.976 \\
\hline Use of insulin & $32(15.2)$ & $20(9.5)$ & $20(9 \cdot 3)$ & $23(11.0)$ & 0.194 \\
\hline Use of TZD & $23(10.9)$ & $30(14.2)$ & $18(8.4)$ & $24(11.5)$ & 0.671 \\
\hline Current smoker $^{\mathrm{d}}$ & $20(18.0)$ & $24(20.3)$ & $32(27.1)$ & $36(31.3)$ & 0.009 \\
\hline $\mathrm{HbAlc}, \%$ & $7.9 \pm 1.7$ & $7.8 \pm 1.6$ & $7.8 \pm 1.7$ & $8.1 \pm 1.9$ & 0.288 \\
\hline Fasting glucose, mg/dL & $146.6 \pm 55 \cdot 7$ & $146.6 \pm 48.7$ & $147 \cdot 4 \pm 54 \cdot 1$ & $152.8 \pm 57 \cdot 3$ & 0.590 \\
\hline Total cholesterol, mg/dL & $160.9 \pm 24.5$ & $158.3 \pm 20.9$ & $159.6 \pm 19.2$ & $162.1 \pm 22.2$ & 0.305 \\
\hline Triglycerides, mg/dL & $99.8 \pm 45.2$ & $125.8 \pm 70.6$ & $138.8 \pm 70.9$ & $167 \cdot 3 \pm 80.3$ & $<0.001$ \\
\hline HDL-C, mg/dL & $65 \cdot 3 \pm 16.0$ & $54.5 \pm 11.5$ & $47 \cdot 9 \pm 9.8$ & $41.6 \pm 12.0$ & $<0.001$ \\
\hline LDL-C, mg/dL & $79.0(65.0-89.0)$ & $81.0(70.0-91.0)$ & $87.0(77.0-93.0)$ & $89.0(81.0-94.0)$ & $<0.001$ \\
\hline C-peptide, ng/mL & $1.6 \pm 0.7$ & $1.7 \pm 0.8$ & $1.8 \pm 0.8$ & $2.1 \pm 1.0$ & $<0.001$ \\
\hline $\mathrm{Kitt}, \% / \mathrm{min}$ & $2.3 \pm 0.9$ & $2.2 \pm 1.0$ & $2.2 \pm 1.0$ & $2.0 \pm 1.0$ & 0.031 \\
\hline
\end{tabular}

Values are presented as mean $\pm \mathrm{SD}$, number (\%), or median (interquartile range).

CIMT, carotid intima-media thickness; SBP, systolic blood pressure; DBP, diastolic blood pressure; DM, diabetes mellitus; TZD, thiazolidinedione; HbA1c, glycated hemoglobin; HDL-C, high density lipoprotein cholesterol; LDL-C, low density lipoprotein cholesterol; Kitt, rate constant for plasma glucose disappearance.

${ }^{a}$ Mean CIMT is defined as the mean value of six measurements from right and left carotid arteries.

${ }^{\mathrm{b}}$ Carotid plaque is defined as focal structures encroaching into the arterial lumen of at least $0.5 \mathrm{~mm}$ or $50 \%$ of the surrounding intima-media thickness value, or a thickness $>1.5 \mathrm{~mm}$.

${ }^{\mathrm{c}}$ Carotid atherosclerosis is defined as having a carotid plaque or diffuse thickening of carotid wall (mean CIMT $\geq 1.0 \mathrm{~mm}$ ).

${ }^{\mathrm{d}}$ Value was measured in 462 subjects.

[OR], 6.73; 95\% confidence interval [CI], 2.30 to 19.71; $p$ $=0.001$ ) and females (OR, 12.15; 95\% CI, 3.77 to 39.14; $p$ $<0.001$ ) when the ApoB/ApoA-I ratio was analyzed as a continuous variable in a logistic regression model that was fully adjusted for baseline parameters (data not shown).

Further, the association between the ApoB/ApoA-I ratio and mean CIMT was analyzed by Pearson correlation coefficient (Fig. 2). ApoB/ApoA-I was positively correlat- ed with mean CIMT in both men $(r=0.09, p=0.047)$ and women $(r=0.14, p=0.007)$. Finally, a significant positive correlation was observed in all T2DM subjects $(r=0.12$, $p<0.001$ ).

\section{Predictive value of the ApoB/ApoA-I ratio for detect- ing carotid atherosclerosis}

The optimal cutoff value of the ApoB/ApoA-I ratio for detecting carotid atherosclerosis was 0.57 in ROC analy- 
sis of all subjects, with a sensitivity of $58.0 \%$ and a specificity of $55.1 \%$. The cutoff value was 0.60 in men and 0.56 in women. The AUC of the unadjusted ROC curve was 0.61 (95\% CI, 0.57 to $0.64 ; p<0.001)$, and the AUC of the ROC curve adjusted for age, sex, BMI, systolic $\mathrm{BP}$, duration of diabetes, $\mathrm{HbArc}$, use of statins, use of anti-hypertensive drugs, TG, HDL-C, log-transformed LDL-C, and Kitt was 0.75 (95\% CI, 0.72 to $0.78 ; p<0.001$ ) (Fig. 3). Using 0.57 as the cut-off value, the OR for carotid atherosclerosis was 1.47 (95\% CI, 1.01 to $2.15 ; p=0.044$ ) after adjusting for age, sex, BMI, systolic BP, duration of diabetes, $\mathrm{HbA1c}$, use of statins, use of anti-hypertensive drugs, TG, HDL-C, log-transformed LDL-C, and Kitt.

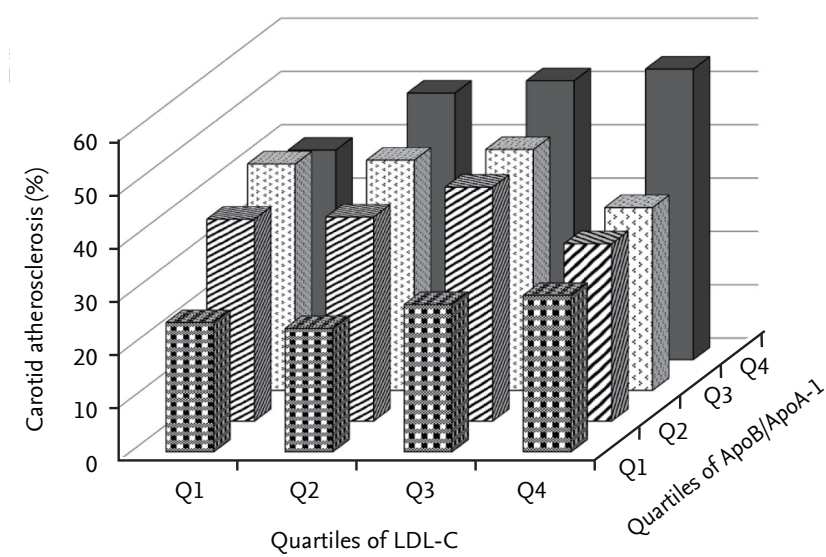

Figure 1. Prevalence of carotid atherosclerosis according to low density lipoprotein cholesterol (LDL-C) quartile and the apolipoprotein (Apo) B/ApoA-I ratio quartile.

\section{DISCUSSION}

This study showed that a high ApoB/ApoA-I ratio was significantly associated with carotid atherosclerosis in T2DM patients with well-controlled LDL-C concentrations, regardless of conventional CVD risk factors and insulin sensitivity. The distribution of ApoB/ApoA-I ratios was heterogeneous among the study subjects, despite the controlled LDL-C levels lower than $100 \mathrm{mg} / \mathrm{dL}$. In addition, higher LDL-C concentrations were not always associated with a higher prevalence of carotid atherosclerosis.

Apos are crucial components of plasma lipoprotein particles. ApoB has two major components: ApoB-48, which complexes with dietary TG and free cholesterol from the gut lumen; and ApoB-10o, which is present in LDL, intermediate density lipoprotein, and very low density lipoprotein (VLDL) particles [28]. The total number of ApoB particles indicates the total number of atherogenic lipoproteins, because one ApoB molecule is present in each of these lipoproteins [9]. ApoA includes ApoA-I, the main constituent of HDL, which removes excess cholesterol from tissues via lecithin cholesterol acyltransferase, and ApoA-II, which inhibits hepatic and lipoprotein lipase activity by reducing plasma HDL levels [29]. Thus, the ApoB/ApoA-I ratio represents the balance between atherogenic and anti-atherogenic particles, and may improve the prediction of CVD risk.

Several large studies found that the ApoB/ApoA-I ratio

Table 3. Risk for carotid atherosclerosis according to the ApoB/ApoA-I ratio

\begin{tabular}{|c|c|c|c|c|c|c|c|}
\hline & \multicolumn{5}{|c|}{ Quartiles of ApoB/ApoA-I ratio } & \multirow{2}{*}{$\begin{array}{l}\text { Continuous vari- } \\
\text { able OR ( } 95 \% \mathrm{CI})\end{array}$} & \multirow[b]{2}{*}{$p$ value } \\
\hline & $\begin{array}{l}\text { Quartile } 1 \\
(0.16-0.48)\end{array}$ & $\begin{array}{l}\text { Quartile } 2 \\
(0.49-0.57)\end{array}$ & $\begin{array}{l}\text { Quartile } 3 \\
(0.58-0.70)\end{array}$ & $\begin{array}{l}\text { Quartile } 4 \\
\text { (0.71-1.59) }\end{array}$ & $p$ for trend & & \\
\hline Crude model & 1 (reference) & $1.81(1.20-2.75)$ & $2.11(1.40-3.18)$ & $2.67(1.77-4.03)$ & $<0.001$ & $9.51(4.32-20.91)$ & $<0.001$ \\
\hline Model $1^{\mathrm{a}}$ & 1 (reference) & $1.84(1.18-2.85)$ & $2.21(1.42-3.43)$ & $3.01(1.93-4.67)$ & $<0.001$ & $13.67(5.76-32.49)$ & $<0.001$ \\
\hline Model $2^{b}$ & 1 (reference) & $1.75(1.12-2.74)$ & $2.12(1.36-3.31)$ & $2.76(1.76-4.34)$ & $<0.001$ & $12.27(5.01-30.09)$ & $<0.001$ \\
\hline Model $3^{c}$ & 1 (reference) & $1.57(0.98-2.53)$ & $1.75(1.04-2.93)$ & $2.14(1.21-3.79)$ & 0.014 & $10.05(3.26-30.95)$ & $<0.001$ \\
\hline Model $4^{\mathrm{d}}$ & 1 (reference) & $1.57(0.98-2.53)$ & $1.75(1.04-2.93)$ & $2.14(1.21-3.79)$ & 0.014 & $10.05(3.26-30.97)$ & $<0.001$ \\
\hline
\end{tabular}

Apo, apolipoprotein; OR, odds ratio; CI, confidence interval.

${ }^{\text {a }}$ Model 1 was adjusted for age and sex.

${ }^{\mathrm{b}}$ Model 2 was additionally adjusted for body mass index, systolic blood pressure, duration of diabetes mellitus, glycated hemoglobin, use of statins, and use of anti-hypertensive drugs.

${ }^{c}$ Model 3 was additionally adjusted for triglycerides, high density lipoprotein cholesterol, and log-transformed low density lipoprotein cholesterol

${ }^{\mathrm{d}}$ Model 4 was additionally adjusted for rate of plasma glucose disappearance (Kitt). 


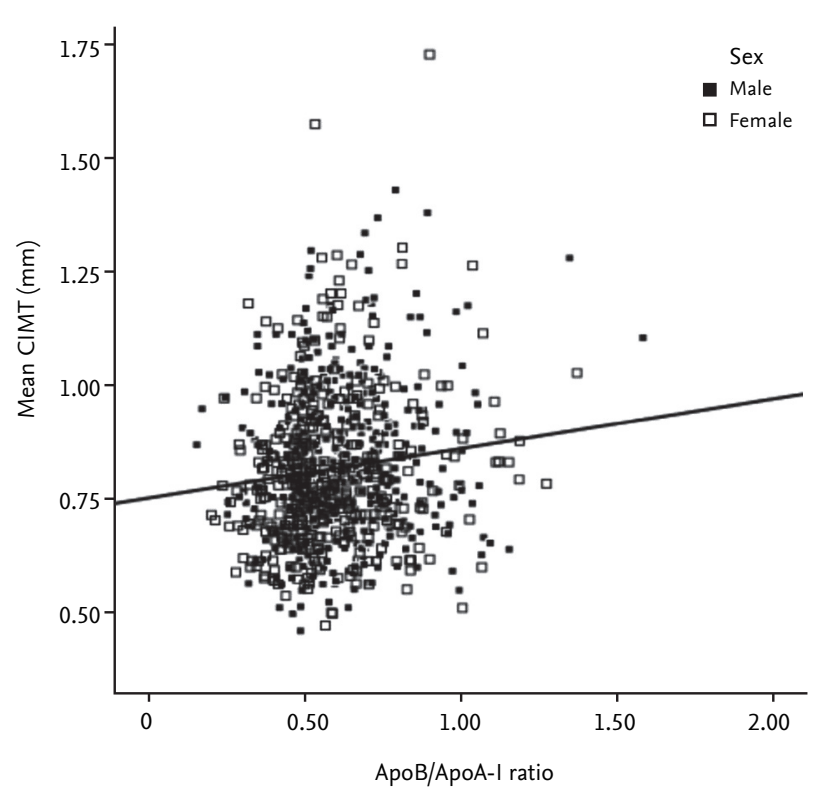

Figure 2. Correlation between the apolipoprotein (Apo) B/ ApoA-I ratio and mean carotid intima-media thickness (CIMT). Black squares for male and white squares for female.

was strongly predictive of MI risk. The AMORIS (Apolipoprotein-related MOrtality RISk) study showed that ApoB, ApoA-I, and the ApoB/ApoA-I ratio were stronger predictors of fatal MI risk than total cholesterol or TG [14]. The INTERHEART (effect of potentially modifiable risk factors associated with myocardial infarction in 52 countries) study, which enrolled patients in 52 countries, demonstrated that the non-fasting ApoB/ ApoA-I ratio was superior to any other cholesterol ratios for estimating acute MI risk [30]. The PRIME (PRospective Epidemiologic study of Myocardial Infarction) study used a prospective cohort that included healthy middle-aged men, and also found that the ApoB/ApoA-I ratio significantly predicted future $\mathrm{CHD}$ and ischemic stroke [31]. Finally, a meta-analysis of 23 relevant prospective studies revealed that high ApoB/ApoA-I ratios resulted in a 1.8-fold increase in the risk for CHD compared to low ratios [32]. Even in subjects with LDL-C levels less than $100 \mathrm{mg} / \mathrm{dL}, 89.7 \%$ of subjects who had higher ApoB/ApoA-I ratios (> o.8) were diagnosed with angiographically proven coronary artery disease (CAD), and the ApoB/ApoA-I ratio was also positively correlated with CAD severity [33]. In addition, both overt CVD and subclinical atherosclerosis were significantly associated with the ApoB/ApoA-I ratio. An increase in the ApoB/
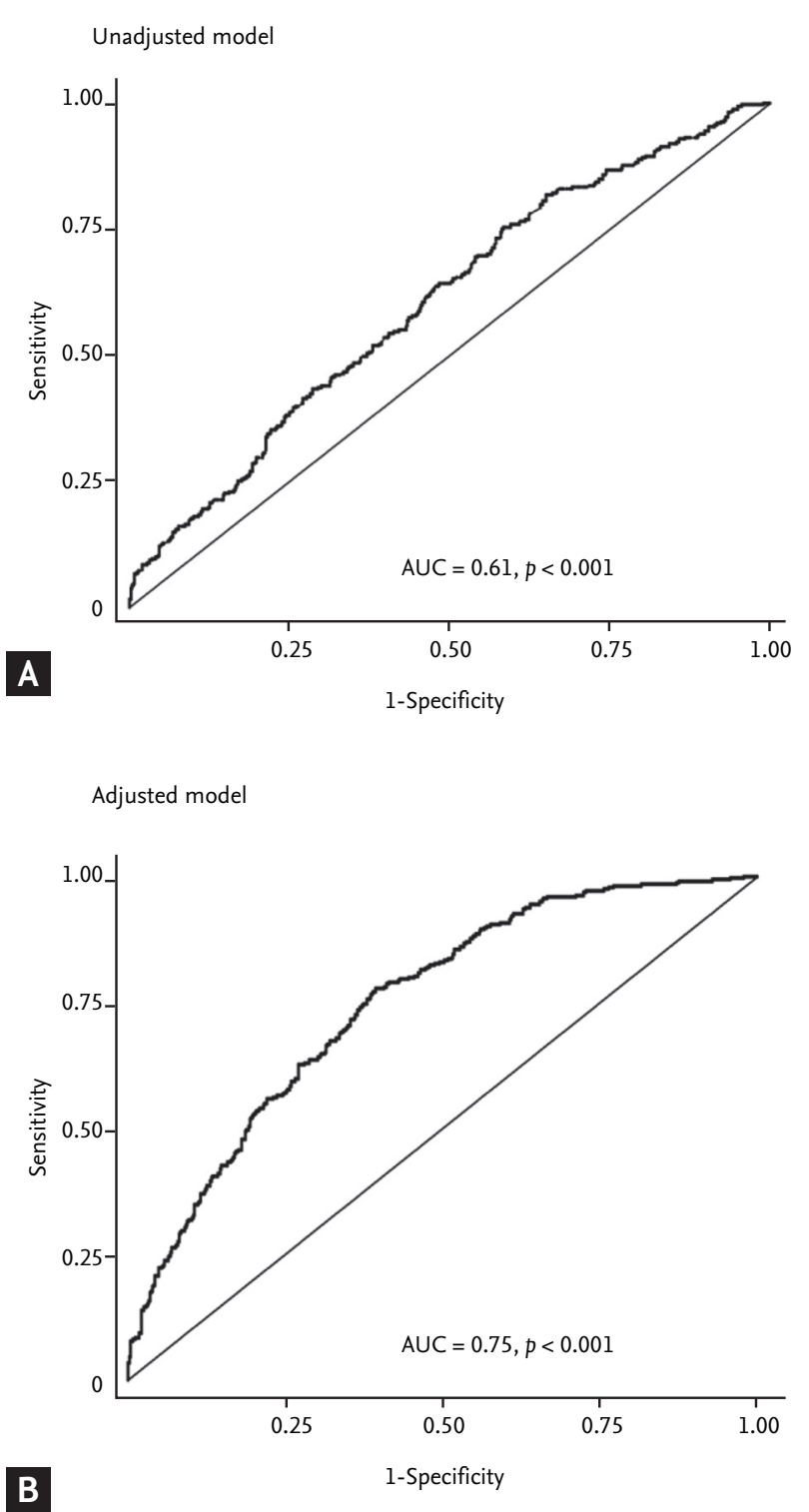

Figure 3. Receiver operating characteristic curves of the apolipoprotein (Apo) B/ApoA-I ratio for detecting carotid atherosclerosis. (A) The area under the curve (AUC) of the ApoB/ ApoA-I ratio before adjusting for covariates. (B) The AUC of the ApoB/ApoA-I ratio with adjusting for age, sex, body mass index, systolic blood pressure, duration of diabetes, glycated hemoglobin, use of statins, and use of anti-hypertensive drugs, triglycerides, high density lipoprotein cholesterol, and log-transformed low density lipoprotein cholesterol, and the rate of plasma glucose disappearance (Kitt).

ApoA-I ratio was associated with an over 50\% increased risk for coronary artery stenosis and non-calcified plaque occurrence [34]. The ApoB/ApoA-I ratio was also positively associated with 3-year alterations in CIMT in middle-aged men [35]. 
Diabetic dyslipidemia is accompanied by abnormal lipid concentrations and altered lipoprotein composition. Dyslipidemia in T2DM is usually characterized by hypertriglyceridemia, reduced HDL-C, and more prevalent small dense LDL, while LDL-C concentration is normal or slightly increased $[16,36]$. This dyslipidemia was also found in patients with prediabetes who had higher insulin resistance and relatively normal glycemic indices [37]. Insulin resistance, which plays a key role in T2DM development, enhances the hepatic secretion of VLDL and regulates ApoB degradation. Increased ApoB and TG results in reduced HDL-C, and a consequent increase in the ApoB/ApoA-I ratio [38]. Our results demonstrated a positive correlation between ApoB/ApoA-I ratio quartile and insulin resistance measured by Kitt, although the association between the ApoB/ApoA-I ratio was still significant after adjustment for Kitt in T2DM subjects. However, few studies have been conducted on the association between ApoB/ApoA-I ratio and overt CVD or subclinical atherosclerosis in diabetic patients. One previous population-based cohort study revealed that a higher ApoB/ApoA-I ratio was associated with a higher risk of cardiovascular mortality, independent of non HDL-C in T2DM patients; this association was more evident in patients aged over 70 years [39]. Other cross-sectional studies showed that the ApoB/ApoA-I ratio was positively correlated with CIMT in diabetic patients [33,40].

The AMORIS and INTERHEART studies suggested that an ApoB/ApoA-I ratio of 0.90 for men and 0.80 for women were indicative of a high CVD risk, and values of less than 0.70 in men and 0.60 in women were considered to indicate low CVD risk if no other risk factors were present $[12,14]$. The optimal cutoff value for ApoB/ ApoA-I in this study was lower than previously suggested values obtained in the context of mostly non-diabetic subjects. This suggests that smaller alterations in lipoprotein composition are associated with CVD in patients with diabetes. Incidentally, diabetes is already classified as a risk factor for CVD. Another explanation is that the ApoB/ApoA-I ratio decreased relative to the low concentration of LDL-C.

This study had several limitations. First, we could not determine a causal relationship between the ApoB/ ApoA-I ratio and carotid atherosclerosis due to the cross-sectional design. Second, there were no data about menopausal state leading to changes in lipid profile [41]. Third, there were incomplete smoking history and lack of data about the anti-platelet agents including aspirin or duration of statin treatment, which are known associated factors with atherosclerosis. Lastly, this study was performed at a single center in Korea; hence, it does not represent the general diabetic population. However, in contrast to the previous similar studies [33,40], the strength of our study is that we demonstrated the correlation between ApoB/Apo-I ratio and carotid atherosclerosis, especially among T2DM patients with well-controlled LDL-C.

In conclusion, the ApoB/ApoA-I ratio was independently associated with risk of carotid atherosclerosis in T2DM patients whose LDL-C levels were less than $100 \mathrm{mg} / \mathrm{dL}$. Lowering LDL-C is undoubtedly an effective means of controlling CVD risk, but other lipid-modifying strategies may also be important in specific populations. Although the American College of Cardiology Foundation/American Heart Association and the National Academy of Clinical Biochemistry do not recommend measurement of Apos or any additional lipid parameters beyond a standard lipid panel for CVD risk assessment $[42,43]$, the ApoB/ApoA-I ratio may be a useful marker for CVD risk, especially in T2DM subjects with well-controlled LDL-C levels.

\section{KEY MESSAGE}

1. The apolipoprotein (Apo) B/ApoA-I ratio was significantly associated with carotid atherosclerosis in type 2 diabetes mellitus ( $\mathrm{T} 2 \mathrm{DM}$ ) patients with low density lipoprotein cholesterol (LDL-C) level below $100 \mathrm{mg} / \mathrm{dL}$.

2. Higher LDL-C levels were not always associated with a higher prevalence of carotid atherosclerosis in $\mathrm{T} 2 \mathrm{DM}$ patients.

\section{Conflict of interest}

No potential conflict of interest relevant to this article was reported. 


\section{REFERENCES}

1. American Diabetes Association. 9. Cardiovascular disease and risk management. Diabetes Care 2017;40(Suppl 1):S75-S87.

2. Stone NJ, Robinson JG, Lichtenstein AH, et al. 2013 ACC/ AHA guideline on the treatment of blood cholesterol to reduce atherosclerotic cardiovascular risk in adults: a report of the American College of Cardiology/American Heart Association Task Force on Practice Guidelines. J Am Coll Cardiol 2014;63(25 Pt B):2889-2934.

3. Expert Dyslipidemia Panel of the International Atherosclerosis Society Panel members. An International Atherosclerosis Society Position Paper: global recommendations for the management of dyslipidemia: full report. J Clin Lipidol 2014;8:29-6o.

4. Ha KH, Kim DJ. Current status of managing diabetes mellitus in Korea. Korean J Intern Med 2016;31:845-850.

5. Ai M, Otokozawa S, Asztalos BF, et al. Small dense LDL cholesterol and coronary heart disease: results from the Framingham Offspring Study. Clin Chem 2010;56:967976.

6. Lim TS, Yun JS, Cha SA, et al. Elevated lipoprotein(a) levels predict cardiovascular disease in type 2 diabetes mellitus: a 10-year prospective cohort study. Korean J Intern Med 2016;31:1110-1119.

7. Ivanova EA, Myasoedova VA, Melnichenko AA, Grechko AV, Orekhov AN. Small dense low-density lipoprotein as biomarker for atherosclerotic diseases. Oxid Med Cell Longev 2017;2017:1273042.

8. Cromwell WC, Otvos JD. Heterogeneity of low-density lipoprotein particle number in patients with type 2 diabetes mellitus and low-density lipoprotein cholesterol $<100$ mg/dl. Am J Cardiol 2006;98:1599-1602.

9. Walldius G, Jungner I. The apoB/apoA-I ratio: a strong, new risk factor for cardiovascular disease and a target for lipid-lowering therapy: a review of the evidence. J Intern Med 2006;259:493-519.

10. Kaneva AM, Potolitsyna NN, Bojko ER, Odland JO. The apolipoprotein B/apolipoprotein A-I ratio as a potential marker of plasma atherogenicity. Dis Markers 2015;2015:591454.

11. Millan J, Pinto X, Munoz A, et al. Lipoprotein ratios: physiological significance and clinical usefulness in cardiovascular prevention. Vasc Health Risk Manag 2009;5:757765 .
12. Yusuf S, Hawken S, Ounpuu S, et al. Effect of potentially modifiable risk factors associated with myocardial infarction in 52 countries (the INTERHEART study): case-control study. Lancet 2004;364:937-952.

13. Meisinger C, Loewel H, Mraz W, Koenig W. Prognostic value of apolipoprotein $\mathrm{B}$ and A-I in the prediction of myocardial infarction in middle-aged men and women: results from the MONICA/KORA Augsburg cohort study. Eur Heart J 2005;26:271-278.

14. Walldius G, Jungner I, Holme I, Aastveit AH, Kolar W, Steiner E. High apolipoprotein B, low apolipoprotein A-I, and improvement in the prediction of fatal myocardial infarction (AMORIS study): a prospective study. Lancet 2001;358:2026-2033.

15. Walldius G, Jungner I, Aastveit AH, Holme I, Furberg CD, Sniderman AD. The apoB/apoA-I ratio is better than the cholesterol ratios to estimate the balance between plasma proatherogenic and antiatherogenic lipoproteins and to predict coronary risk. Clin Chem Lab Med 2004;42:13551363.

16. Verges B. Pathophysiology of diabetic dyslipidaemia: where are we? Diabetologia 2015;58:886-899.

17. Kannan S, Mahadevan S, Ramji B, Jayapaul M, Kumaravel V. LDL-cholesterol: Friedewald calculated versus direct measurement-study from a large Indian laboratory database. Indian J Endocrinol Metab 2014;18:502-504.

18. Bonora E, Moghetti P, Zancanaro C, et al. Estimates of in vivo insulin action in man: comparison of insulin tolerance tests with euglycemic and hyperglycemic glucose clamp studies. J Clin Endocrinol Metab 1989;68:374-378.

19. Young RP, Critchley JA, Anderson PJ, Lau MS, Lee KK, Chan JC. The short insulin tolerance test: feasibility study using venous sampling. Diabet Med 1996;13:429-433.

20. Alberti KG, Daly ME, Robinson A, Marshall SM, Mathers JC. The short insulin tolerance test is safe and reproducible. Diabet Med 1999;16:352-353.

21. Park SW, Kim SK, Cho YW, et al. Insulin resistance and carotid atherosclerosis in patients with type 2 diabetes. Atherosclerosis 2009;205:309-313.

22. Chambless LE, Folsom AR, Clegg LX, et al. Carotid wall thickness is predictive of incident clinical stroke: the Atherosclerosis Risk in Communities (ARIC) study. Am J Epidemiol 2000;151:478-487.

23. Hong SN, Park JC, Yoon NS, et al. Carotid artery intima-media thickness in Behcet's disease patients without significant cardiovascular involvement. Korean J Intern 
Med 2008;23:87-93.

24. Baldassarre D, Amato M, Pustina L, et al. Measurement of carotid artery intima-media thickness in dyslipidemic patients increases the power of traditional risk factors to predict cardiovascular events. Atherosclerosis 2007;191:403-408.

25. Naqvi TZ, Lee MS. Carotid intima-media thickness and plaque in cardiovascular risk assessment. JACC Cardiovasc Imaging 2014;7:1025-1038.

26. Touboul PJ, Hennerici MG, Meairs S, et al. Mannheim carotid intima-media thickness and plaque consensus (2004-2006-2011). An update on behalf of the advisory board of the 3 rd, $4^{\text {th }}$ and $5^{\text {th }}$ watching the risk symposia, at the 13th, 15th and 2oth European Stroke Conferences, Mannheim, Germany, 2004, Brussels, Belgium, 2006, and Hamburg, Germany, 2011. Cerebrovasc Dis 2012;34:290296.

27. Kim SK, Choi YJ, Huh BW, et al. Ratio of waist-to-calf circumference and carotid atherosclerosis in Korean patients with type 2 diabetes. Diabetes Care 2011;34:20672071.

28. Packard CJ, Shepherd J. Lipoprotein heterogeneity and apolipoprotein B metabolism. Arterioscler Thromb Vasc Biol 1997;17:3542-3556.

29. Walldius G, Jungner I. Apolipoprotein B and apolipoprotein A-I: risk indicators of coronary heart disease and targets for lipid-modifying therapy. J Intern Med 2004;255:188-205.

30. McQueen MJ, Hawken S, Wang X, et al. Lipids, lipoproteins, and apolipoproteins as risk markers of myocardial infarction in 52 countries (the INTERHEART study): a case-control study. Lancet 2008;372:224-233.

31. Canoui-Poitrine F, Luc G, Bard JM, et al. Relative contribution of lipids and apolipoproteins to incident coronary heart disease and ischemic stroke: the PRIME Study. Cerebrovasc Dis 2010;30:252-259.

32. Thompson A, Danesh J. Associations between apolipoprotein $\mathrm{B}$, apolipoprotein $\mathrm{AI}$, the apolipoprotein $\mathrm{B} / \mathrm{AI}$ ratio and coronary heart disease: a literature-based meta-analysis of prospective studies. J Intern Med 2006;259:481-492.

33. Jadhav UM, Kadam NN. Apolipoproteins: correlation with carotid intimamedia thickness and coronary artery disease. J Assoc Physicians India 2004;52:370-375.

34. Jung CH, Hwang JY, Shin MS, et al. Association of apoli- poprotein b/apolipoprotein A1 ratio and coronary artery stenosis and plaques detected by multi-detector computed tomography in healthy population. J Korean Med Sci 2013;28:709-716.

35. Wallenfeldt K, Bokemark L, Wikstrand J, Hulthe J, Fagerberg B. Apolipoprotein B/apolipoprotein A-I in relation to the metabolic syndrome and change in carotid artery intima-media thickness during 3 years in middle-aged men. Stroke 2004;35:2248-2252.

36. Goldberg IJ. Clinical review 124: diabetic dyslipidemia: causes and consequences. J Clin Endocrinol Metab 2001;86:965-971.

37. Haffner SM, Mykkanen L, Festa A, Burke JP, Stern MP. Insulin-resistant prediabetic subjects have more atherogenic risk factors than insulin-sensitive prediabetic subjects: implications for preventing coronary heart disease during the prediabetic state. Circulation 2000;101:975980.

38. Sniderman AD, Faraj M. Apolipoprotein B, apolipoprotein A-I, insulin resistance and the metabolic syndrome. Curr Opin Lipidol 2007;18:633-637.

39. Bruno G, Merletti F, Biggeri A, et al. Effect of age on the association of non-high-density-lipoprotein cholesterol and apolipoprotein $\mathrm{B}$ with cardiovascular mortality in a Mediterranean population with type 2 diabetes: the Casale Monferrato study. Diabetologia 2006;49:937-944.

40. Dahlen EM, Lanne T, Engvall J, et al. Carotid intima-media thickness and apolipoprotein B/apolipoprotein A-I ratio in middle-aged patients with type 2 diabetes. Diabet Med 2009;26:384-390.

41. Anagnostis P, Stevenson JC, Crook D, Johnston DG, Godsland IF. Effects of menopause, gender and age on lipids and high-density lipoprotein cholesterol subfractions. Maturitas 2015;81:62-68.

42. Goff DC Jr, Lloyd-Jones DM, Bennett G, et al. 2013 ACC/ AHA guideline on the assessment of cardiovascular risk: a report of the American College of Cardiology/American Heart Association Task Force on Practice Guidelines. Circulation 2014;129(25 Suppl 2):S49-S73.

43. NACB LMPG Committee Members, Myers GL, Christenson RH, et al. National Academy of Clinical Biochemistry Laboratory Medicine Practice guidelines: emerging biomarkers for primary prevention of cardiovascular disease. Clin Chem 2009;55:378-384. 
Supplementary Table 1. Univariate logistic regression analysis for the presence of carotid atherosclerosis

\begin{tabular}{|c|c|c|}
\hline Variable & Odds ratio (95\% CI) & $p$ value \\
\hline Age, yr & $1.09(1.07-1.11)$ & $<0.001$ \\
\hline Male sex & $1.39\left(1.05^{-1.84}\right)$ & 0.021 \\
\hline Body mass index, $\mathrm{kg} / \mathrm{m}^{2}$ & $1.06(1.01-1.11)$ & 0.010 \\
\hline $\mathrm{SBP}, \mathrm{mmHg}$ & $1.02(1.01-1.03)$ & $<0.001$ \\
\hline $\mathrm{DBP}, \mathrm{mmHg}$ & $1.00(0.99-1.02)$ & 0.628 \\
\hline DM duration, yr & $1.06(1.04-1.08)$ & $<0.001$ \\
\hline Use of statins & $1.57(1.11-2.21)$ & 0.011 \\
\hline Use of anti-hypertensive drugs (yes) & $1.58(1.18-2.13)$ & 0.002 \\
\hline Use of insulin (yes) & $1.31(0.85-2.01)$ & 0.222 \\
\hline Use of TZD (yes) & $1.37(0.89-2.11)$ & 0.149 \\
\hline HbAıc, \% & $1.07(0.99-1.16)$ & 0.108 \\
\hline Fasting glucose, mg/dL & $1.00(0.99-1.00)$ & 0.813 \\
\hline Total cholesterol, mg/dL & $1.00(0.99-1.01)$ & 0.188 \\
\hline Triglycerides, mg/dL & $1.01(1.00-1.04)$ & 0.042 \\
\hline $\mathrm{HDL}-\mathrm{C}, \mathrm{mg} / \mathrm{dL}$ & $0.99(0.98-0.99)$ & 0.002 \\
\hline Log-transformed LDL-C, mg/dL & $7.71(1.53-38.75)$ & 0.013 \\
\hline ApoB, mg/dL & $1.02(1.01-1.02)$ & $<0.001$ \\
\hline ApoA-I, mg/dL & $0.99(0.98-0.99)$ & 0.001 \\
\hline ApoB/ApoA-I ratio & $9.51(4.32-19.57)$ & $<0.001$ \\
\hline C-peptide, ng/mL & $1.20(1.02-1.42)$ & 0.031 \\
\hline Kitt, \%/min & $0.78(0.68-0.90)$ & 0.001 \\
\hline
\end{tabular}

CI, confidence interval; SBP, systolic blood pressure; DBP, diastolic blood pressure; TZD, thiazolidinedione; HbAıc, glycated hemoglobin; HDL-C, high density lipoprotein cholesterol; LDL-C, low density lipoprotein cholesterol; Apo, apolipoprotein; Kitt, rate constant for plasma glucose disappearance. 


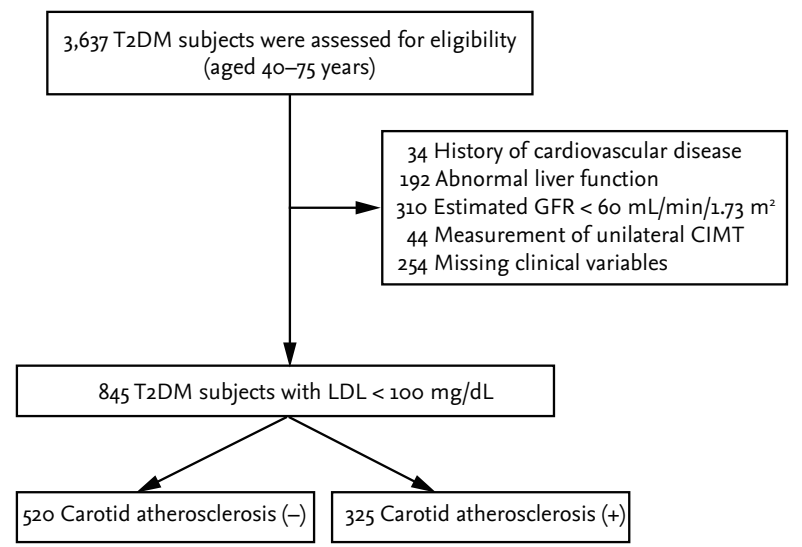

Supplementary Figure 1. Selection of study subjects. T2DM, type 2 diabetes mellitus; GFR, glomerular filtration rate; CIMT, carotid intima-media thickness; LDL, low density lipoprotein. 